\title{
Editorial to the thematic issue: Ecological interactions in Central European forest under climate change
}

Dear readers,

Recent decades were characterized by dramatic changes in the environment, which challenged management of natural resources, including forestry. Many of these changes were driven by increasing air temperature, changing precipitation patterns, and increasing frequency of climate extremes. These dynamics affected forest ecosystems across Europe, triggering large pulses of tree mortality and species redistribution, and changing long-term disturbance regimes in many regions. Central Europe is a specific region where processes that are characteristic for low and high latitudes of Europe interact and generate unique ecosystem dynamics. Understanding these processes is central for informing forest management under climate change that needs to accommodate new concepts and address the emergent ecosystem dynamics.

Central European Forestry Journal is published jointly by National Forest Centre - Forest Research Institute Zvolen and Czech University of Life Sciences in Prague - Faculty of Forestry and Wood Sciences. We are pleased to bring to your attention the Special Issue entitled Ecological Interactions in Central European forest under climate change aiming at various ecological interplays in forest ecosystems facing the ongoing changes in climate. This issue presents a collection of six papers endeavouring to fill some gaps in our current understanding of the dynamics of Central European forests.

The article Carbon sequestration in living biomass of Slovak forests: recent trends and future projection (Barka et al.) informs about the carbon sequestration potential of Slovak forests during the next three decades. The authors used a model-based approach to quantify the amount of sequestered carbon under different management regimes, suggesting that changes in harvest timing and intensity are potent means for increasing the amount of carbon stored in the forest living biomass.

A study Changes in diversity of protected scree and herb-rich beech forest ecosystems over 55 years (Hájek et al.) is looking backward and explores changes in structure and herb layer composition of unique forest types, scree and herb-rich beech forests, over last 55 years, some of these changes reflecting on the ongoing changes in climate.

Roessiger et al. investigated the risk of stand-replacing disturbances to spruce stands, and options for alleviating this risk by admixing other trees species than spruce. The study A high proportion of Norway spruce in mixed stands increases probability of stand failure provided sound recommendations for forest management that should increasingly focus on comprehensive risk management rather than on the reductionist focus on productivity.

A paper Physiological vitality of Norway spruce (Picea abies L.) stands along an altitudinal gradient in Tatra National Park (Jamnická et al.) presents ecophysiological research of disturbed spruce stands in the mountain environment of the High Tatra Mts. The authors focused on tree-level processes such as tree growth, mineral nutrition of needles, and photosynthetic efficiency, informing about potential drivers of physiological performance of trees.

A paper Impact of the European bark beetle Ips typographus on biochemical and growth properties of wood and needles in Siberian spruce Picea obovata (Konôpková et al.) investigated how infestation by bark beetles affects biochemical properties of wood and needles of the Siberian spruce. The authors present interesting finding about the responses of photosynthesis-related pigments, extending our understanding of tree-pest interactions, and perhaps also informing efforts on early detection of infested trees via changes in their spectral reflectance.

The last paper The response of Pinus species to ozone uptake in different climate regions of Europe highlighted the fact that there are also other agents adversely affecting forest conditions in Central Europe than broadly studied drought, wind or bark beetles. Bičárová et al. investigated ozone injury to Pinus mugo and Pinus cembra in two mountain environments in Slovakia and France. The authors pointed out the differences in sensitivity of the two species and suggested interesting methodological improvements for mapping the effects of ozone on trees.

We believe that this diverse collection of studies will attract the readership and highlight some unique features of the Central European forests and forestry.

Zuzana Sitková \& Tomáš Hlásny

Editors of the issue 